\title{
The activation of PI 3-kinase/Akt pathway is involved in the acute effects of simvastatin against ischaemia and reperfusion-induced arrhythmias in anaesthetised dogs
}

\author{
Gábor Kisvári ${ }^{a}$, Mária Kovács ${ }^{a}$, György Seprényi ${ }^{b}$, Ágnes Végh ${ }^{a, *}$ \\ a Department of Pharmacology and Pharmacotherapy, University of Szeged, Albert-Szent Györgyi Medical Centre, Szeged, Hungary \\ ${ }^{\mathrm{b}}$ Department of Medical Biology, University of Szeged, Albert-Szent Györgyi Medical Centre, Szeged, Hungary
}

\section{A R T I C L E I N F O}

\section{Article history:}

Received 2 July 2015

Received in revised form

1 October 2015

Accepted 12 November 2015

Available online 17 November 2015

Keywords:

Simvastatin

Nitric oxide

Ischaemia/reperfusion

Arrhythmias

Wortmannin

\begin{abstract}
A B S T R A C T
The objective of this study was to examine whether the PI3-kinase/Akt pathway is involved in the activation of endothelial nitric oxide synthase (eNOS) and in the subsequent increase of nitric oxide (NO) production that has been proved to play a role in the antiarrhythmic effect of acute simvastatin treatment in anaesthetised dogs, subjected to a 25 min occlusion and reperfusion of the left anterior descending coronary artery. Using the same model, 12 dogs out of the 26 controls (given the solvent of simvastatin) and 11 dogs out of the 23 animals treated with intracoronary administered simvastatin $(0.1 \mathrm{mg} / \mathrm{kg}), \mathrm{were}$ now received wortmannin $(1.5 \mathrm{mg} / \mathrm{kg}$, ic.), a selective inhibitor of PI3-kinase. In another 13 dogs the effects of DMSO (0.1\%), the vehicle of wortmannin, were examined. Compared to the controls, simvastatin markedly reduced the severity of ischaemia (epicardial ST-segment, inhomogeneity) and ventricular arrhythmias that were reversed (except the occlusion-induced ventricular fibrillation [VF; 50\%, $0 \%, 0 \%]$ ) by the administration of wortmannin. Thus in these groups there were $310 \pm 45,62 \pm 14$, $307 \pm 59$ ectopic beats, $7.1 \pm 1.4,0.3 \pm 0.2,4.3 \pm 1.3$ tachycardiac episodes that occurred $93 \%, 17 \%$ and $73 \%$ of the dogs during occlusion, whereas survival following reperfusion was $0 \%, 67 \%$ and $0 \%$, respectively. Simvastatin also increased the phosphorylation of eNOS and the plasma nitrate/nitrite levels, but reduced myocardial superoxide production on reperfusion. These effects of simvastatin were also abolished in the presence of wortmannin. We conclude that the NO-dependent antiarrhythmic effect of simvastatin involves the rapid activation of eNOS through the stimulation of the PI3-kinase/Akt pathway. (c) 2015 Elsevier B.V. All rights reserved.
\end{abstract}

\section{Introduction}

There is substantial evidence that chronic statin treatment has many salutary effects, among which the most important one is, perhaps, a reduction in mortality due to sudden cardiac death (e.g. Lipid Study Group, 1998; Gould et al., 2007; Sever et al., 2008). It has been proposed that these beneficial cardioprotective effects, at least in part, are independent from the lipid lowering effects of statins, since the protection is apparent even under normocholesterolemic conditions (e.g. LIPID Study Group, 1998; Lefer et al., 2001; Chen et al., 2003). Although the precise mechanism through which statins yield cardioprotection is still not well established, clinical and experimental studies suggest that nitric oxide (NO), generated via the activation of endothelial nitric oxide synthase (eNOS), may play a mediator role (Altun et al., 2014; Athyros et al.,

\footnotetext{
* Correspondence to: Department of Pharmacology and Pharmacotherapy, University of Szeged, Albert Szent-Györgyi Faculty of Medicine, Dóm tér 12, P.O. Box 427, H-6720 Szeged, Hungary.

E-mail address: vegh.agnes@med.u-szeged.hu (Á. Végh).
}

2014; Wang et al., 2014). The mechanisms by which statins may activate eNOS are even less understood; the prevention of the oxLDL-mediated down-regulation of eNOS mRNA and protein levels (Hernández-Perera et al., 1998), as well as the up-regulation of eNOS by blocking the synthesis of those isoprenoid intermediates of the cholesterol synthesis pathway that are involved in the posttranslational modification of proteins which regulate eNOS expression (Laufs et al., 1997; Laufs and Liao, 1998), were suggested as potential mechanisms for eNOS activation during chronic statin administration.

More recent studies emphasise that the acute administration of statins may also provide cardioprotection. The first evidence for this resulted from the study of Wolfrum et al. (2004), showing that in anaesthetised rats subjected to coronary artery occlusion, simvastatin administration just prior to reperfusion, markedly reduced infarct size, increased PI 3-kinase activity, as well as

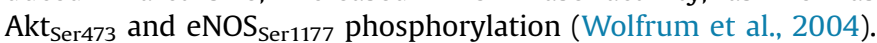
Similarly, we showed in anaesthetised dogs that a single dose of simvastatin, given prior to a 25 min coronary artery occlusion, significantly reduced the severity of the occlusion-induced 
ventricular arrhythmias and increased survival from the combined ischaemia and reperfusion insult (Kisvári et al., 2014). This marked antiarrhythmic effect of simvastatin was associated with increased eNOS activity and NO production, since the protection, except that against the occlusion-induced ventricular fibrillation, was abolished by the administration of the NOS inhibitor L-NAME (Kisvári et al., 2014).

Following this line of reasoning, in this study we aimed to investigate the NO-dependent antiarrhythmic effect of acute simvastatin administration, primary focusing on those signalling pathways that may result in rapid activation of eNOS. One such a pathway, which has been proposed to activate eNOS through phosphorylation within minutes, would be the PI 3-kinase/Akt signalisation (Laufs and Liao, 1998). There already have evidence that following acute simvastatin administration the activation of the PI 3-kinase/Akt/eNOS cascade is involved in the increase of NO synthesis in endothelial cells (Kureishi et al., 2000), and in the reduction of infarct size (Wolfrum et al., 2004). Since there is a lack of information that the pronounced antiarrhythmic effect of a single dose of simvastatin attains also through the stimulation of the PI 3-kinase/Akt/eNOS, we have designed studies to examine this, using the PI 3-kinase inhibitor wortmannin in our canine model of ischaemia and reperfusion.

\section{Materials and methods}

\subsection{Ethics statement}

The origin and upkeep of the dogs used in our experiments were in accord with Hungarian law (XXVIII, chapter IV, paragraph 31 ) regarding the use of large experimental animals, which conforms to the Guide for the Care and Use of Laboratory Animals (ILAR, 1996), and also conformed to Directive 2010/63/EU of the European Parliament. The protocols were approved by the Ethical Committee for the Protection of Animals in Research of the University of Szeged, Szeged, Hungary (approval number: I-74-52012) and by the Department of Animal Health and Food Control of the Ministry of Agriculture and Rural Development (authority approval number XIII/1211/2012).

\subsection{Animals and surgical preparation}

Inbred mongrel dogs of both sexes with a mean body weight of $22 \pm 2 \mathrm{~kg}$ were used. Before the experiments, the dogs were housed in an animal room (temperature $20^{\circ} \mathrm{C}$; humidity from $40 \%$ to $70 \%$; lighting $12 \mathrm{~h}$ per day; two animals per pen) for at least two weeks and fed a standard diet with ad libitum access to water. Food was withdrawn $24 \mathrm{~h}$ before anaesthesia. The surgical procedures were similar to those described previously (Kisvári et al., 2014). In brief, the dogs were lightly anaesthetised with sodium pentobarbitone (30 mg/kg i.v.; Sigma, St. Louis, MO, USA) and the right femoral vein was prepared and catherised for the administration of further anaesthetic (mixture of chloralose and urethane, 60 and $200 \mathrm{mg} / \mathrm{kg}$, respectively; Sigma, St. Louis, MO, USA) to maintain anaesthesia. The depth of anaesthesia was monitored by the examination of the cornea and pain reflexes, as well as by measuring the blood pressure. The animals were then intubated, and ventilated with room air using a Harvard respirator (Harvard Apparatus, Natick, MA, USA) at a rate and volume sufficient to maintain arterial blood gases and $\mathrm{pH}$ within physiological limits (Végh et al., 1992a). Body temperature was measured from the mid-oesophagus, and maintained by a heating pad at $37 \pm 0.5^{\circ} \mathrm{C}$.

A polyethylene catheter was inserted into the right femoral artery to measure arterial blood pressure (systolic and diastolic). A Millar tip catheter (5F, Millar Instruments, USA) was introduced, via the left carotid artery, into the left ventricle (LV) to detect changes in systolic (LVSP) and end-diastolic (LVEDP) pressures as well as in $\mathrm{LVdP} / \mathrm{dt}$.

A thoracotomy was performed at the fifth intercostal space and the anterior descending branch of the left coronary artery (LAD) was prepared for occlusion just proximal to the first main diagonal branch. Distal to the occlusion site a smaller side branch of the same artery was also prepared and cannulated for the local administration of drugs (simvastatin and wortmannin) and vehicles (solvent of simvastatin and DMSO). Another catheter was positioned through the right jugular vein into the coronary sinus to obtain blood samples for the assessment of plasma nitrate/nitrite $\left(\mathrm{NO}_{\mathrm{x}}\right)$ levels. In some dogs from each group, the left circumflex (LCX) coronary artery was also prepared to measure coronary blood flow (CBF; ml/min) by means of a transit time Doppler flow probe (Hugo Sachs Electronics, Germany).

The severity of myocardial ischaemia was evaluated by the measurement of changes in the epicardial ST-segment and in the degree of inhomogeneity of electrical activation, using a composite electrode positioned within the potentially ischaemic area as previously described (Végh et al., 1992a; Kisvári et al., 2014). Inhomogeneity was assessed as the greatest delay in activation following coronary artery occlusion, and it was expressed in milliseconds. The composite electrode also contains four unipolar electrodes by which changes in epicardial ST-segment were detected.

Ventricular arrhythmias were assessed according to the Lambeth conventions (Walker et al., 1988) with that modification as outlined previously (Végh et al., 1992a). In brief, the total number of ventricular premature beats (VPBs), the incidence and the number of episodes of ventricular tachycardia (VT; defined as a run of four or more consecutive VPBs at a rate faster than the resting heart rate), and the incidence of ventricular fibrillation (VF) were assessed during the occlusion period. During reperfusion, only the incidence of VF, which is a fatal event in this species, was determined. Dogs that were alive 1-2 min after reperfusion were considered to be survivors.

All parameters, together with a chest lead electrocardiogram, were measured with a Plugsys Haemodynamic Apparatus (Hugo Sachs Electronics, Germany) and recorded on a Graphtec Thermal Array Recorder (Hugo Sachs Electronics, Germany). From the chest lead electrocardiogram the heart rate (HR), the number and incidence of arrhythmias and the QT interval were determined. The QTc was calculated using the Bazett's formula.

\subsection{Measurement of plasma nitrate/nitrite $\left(\mathrm{NO}_{x}\right)$ levels}

Plasma nitrate/nitrite $\left(\mathrm{NO}_{\mathrm{x}}\right)$ concentrations were determined by means of the Griess reaction in blood samples taken from the coronary sinus at various time intervals (Fig. 1) as described previously (Kiss et al., 2010; Kisvári et al., 2014). After preparation of blood samples, the absorbance of the azo compound was measured spectrophotometrically at a wavelength of $540 \mathrm{~nm}$ and the total nitrate/nitrite $\left(\mathrm{NO}_{\mathrm{x}}\right)$ concentration $(\mu \mathrm{mol} / \mathrm{l})$ was determined using a standard calibration curve of $\mathrm{NaNO}_{2}$ and $\mathrm{NaNO}_{3}$ (Sigma, St Louis, MO, USA).

\subsection{Determination of eNOS phosphorylation by Western blot}

The total and the phosphorylated forms of eNOS were determined in myocardial samples taken from the left ventricular wall, supplied by the LAD, using the same method described previously (Gönczi et al., 2012; Kovács et al., 2013; Kisvári et al., 2014). After preparation of protein extracts $(100 \mu \mathrm{g})$ the blots were immunolabeled with a polyclonal rabbit antibody for eNOS and a monoclonal mouse anti-eNOS as primary antibody for peNOS 


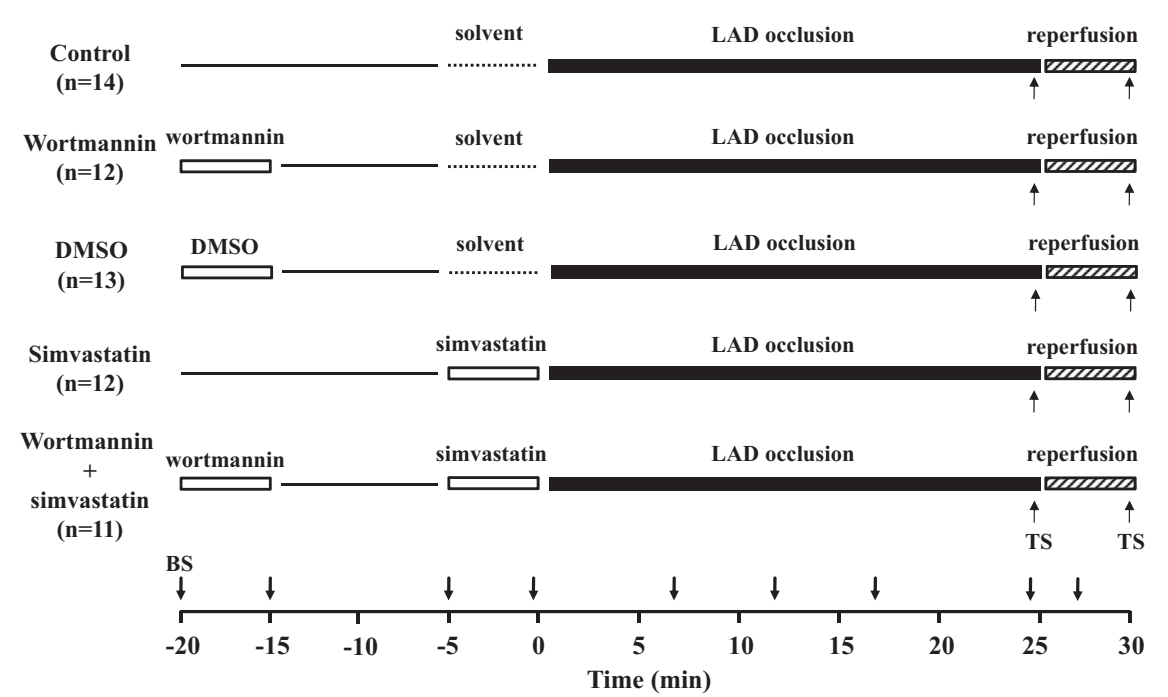

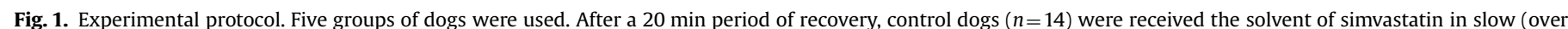

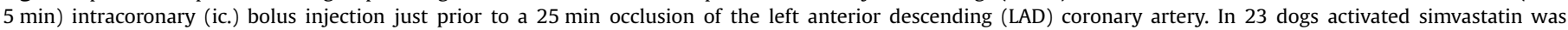

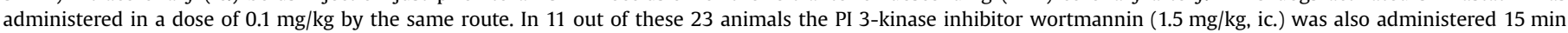

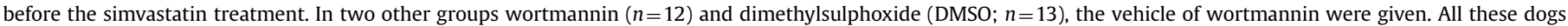

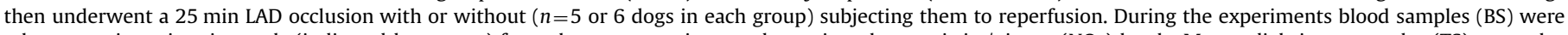

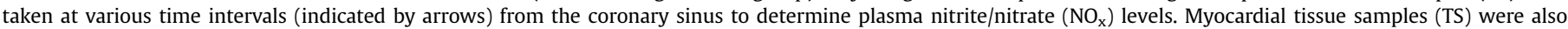
collected at the end of the ischaemic period or $5 \mathrm{~min}$ after reperfusion for further biochemical analyses.

(pS1177, BD Transduction Laboratories ${ }^{\mathrm{TM}}$ ). These were diluted to 1:2500, with an HRP-conjugated anti-rabbit and anti-mouse as secondary antibodies, respectively (Dako, Danmark) in a dilution of 1:8000. Band densities were detected with the ECL Plus kit (GE Healthcare, Buckinghamshire, UK) and developed on Amersham Hyperfilm $^{\mathrm{TM}}$ (GE Healthcare, Buckinghamshire, UK). Pixel intensities of each band were measured using ImageJ software (NIH). Three parallel Western blots were performed for the statistical analysis using Bonferroni correction. On the blots each examined group was compared to the sham-controls. For the verification of equal loading, PVDF membranes were labelled with Coomassie Blue.

An integrated optical density value (the sum of each pixel value corrected to the background) was formed by drawing equal size boxes around the bands. The intensities obtained from both the total and peNOS bands were normalised to this integrated value.

\subsection{Assessment of the generation of reactive oxygen species}

The production of reactive oxygen species (ROS) occurring during reperfusion was determined by dihydroethidium (DHE; Sigma-Aldrich) fluorescence staining as described previously (Kiss et al., 2010, Kisvári et al., 2014). Cryosections (20 $\mu \mathrm{m})$ were produced from tissue blocks (excised from the ischaemic myocardial wall and embedded in OCTC), stained with DHE $(1 \mu \mathrm{mol} / \mathrm{l}$, dissolved in $\mathrm{pH} 7.4$ phosphate buffer solution). A negative control was obtained by blocking the reaction with $\mathrm{N}$-acetyl-L-cysteine (100 mmol/l, Sigma-Aldrich).

Both from the stained and the negative control samples 10-15 serial images were captured by a confocal laser scanning microscope (Olympus FV1000). The pictures were acquired using constant microscope setup Objective $40 \times$ (Zoom 1.5), Texas Red Filter, HV448, Gain 3.75 , Offset $17 \%$, Scan speed $10 \mu$ s (microsecond/ pixel). To avoid a possible difference in the intensity of the background, a mean value was calculated from 6 control slices to which each picture was normalised. The intensity of the fluorescent signals were analysed by Image software (NIH) and expressed in arbitrary units.

\subsection{Preparation of simvastatin solution}

Before the use of simvastatin (Sigma, St Louis, MO, USA) it needs to be converted into an active form. A stock solution containing $25 \mathrm{mg}$ simvastatin, dissolved in $625 \mu \mathrm{l}$ ethanol and $937.5 \mu \mathrm{l}$ $0.1 \mathrm{~N} \mathrm{NaOH}$, was prepared and incubated at $50{ }^{\circ} \mathrm{C}$ for $2 \mathrm{~h}$. The $\mathrm{pH}$ of the solution was adjusted to 7.0 with $1 \mathrm{~N} \mathrm{HCl}$ and stored at $-20{ }^{\circ} \mathrm{C}$ until use. Immediately prior to the experiments an aliquot was taken and diluted in distilled water to obtain the appropriate dose.

\subsection{Experimental protocol}

Dogs were randomly selected into five experimental groups (Fig. 1). ${ }^{1}$ In each group myocardial ischaemia was induced by a 25 min occlusion of the LAD coronary artery. In the control group (C; $n=14)^{1}$ the solvent of simvastatin $(0.5 \mathrm{ml} / \mathrm{min})$, whereas in another group activated simvastatin $(S ; n=12)^{1}$ was administered in a dose of $0.1 \mathrm{mg} / \mathrm{kg}$, in slow (over $5 \mathrm{~min}$ ) intracoronary injection, 5 min prior to the onset of the occlusion. In two other groups, wortmannin alone ( $\mathrm{W} ; n=12$, Sigma) or together with simvastatin $(\mathrm{W}+\mathrm{S} ; n=11)$ was given in a dose of $1.5 \mathrm{mg} / \mathrm{kg}$ also in slow intracoronary injection, $15 \mathrm{~min}$ before the administration of the solvent and simvastatin. Additional 13 dogs were received $0.1 \%$ dimethylsulphoxide (DMSO), the solvent of wortmannin. At the end of the experiments the hearts were stopped by an excess of the anaesthetic, and myocardial tissue samples were collected from the LAD region for further analyses. In at least 5 dogs of each group, sample taking was performed at the end of the $25 \mathrm{~min}$ occlusion period, whereas in dogs that had been subjected to reperfusion, tissue samples were collected either 5 min after reperfusion (these animals were considered as survivors) or at the time when the fibrillation was observed. Eight dogs were used as sham-operated controls (SC; not included in the protocol figure). These dogs were only instrumented, without subjecting them to any treatment, and from which, after the euthanasia, tissue

\footnotetext{
${ }^{1}$ Data obtained from 8 dogs in the control and from 6 dogs in the simvastatin groups were already used in Kisvári et al. (2014).
} 
samples were harvested for measuring eNOS phosphorylation and superoxide production.

\subsection{Assessment of the area at risk}

The "at risk" area affected by the occlusion was assessed using the same method that has been described in detail previously (Végh et al., 1992a). In brief, at the end of the experiments the heart was removed and Patent Blue V dye was infused into the reoccluded LAD artery, whereas saline was infused into the patent left circumflex (LCX) artery, at a pressure similar to that the normal coronary perfusion pressure. The dyed area was cut out and weighed, and the risk area calculated as a percentage of the left ventricular wall together with the septum.

\subsection{Statistical analysis}

The presented values are expressed as the mean \pm S.E.M. and the differences between means were compared by ANOVA for repeated measures and by the one-way ANOVA as appropriate, using the Fisher post hoc test. VPBs and episodes of VT were compared using the Kruskal-Wallis test. The incidences of arrhythmias (such as VT and VF) and survival from the combined ischaemia and reperfusion insult were compared by the Fisher's exact test. Differences between groups were considered significant at $P<0.05$.

\section{Results}

3.1. Haemodynamic changes following the administration of solvent, simvastatin, wortmannin and DMSO, as well as after coronary artery occlusion

These data are summarised in Tables 1 and 2. There were no significant changes in the haemodynamic parameters following the local intracoronary injection of simvastatin and wortmannin, as well as of the vehicle of these drugs (Table 1). Although occlusion of the LAD resulted in significant reductions in arterial blood pressure, LVSP, positive and negative $\mathrm{dP} / \mathrm{dt}_{\max }$, and an increase in LVEDP in all groups, these changes were not substantially different among the groups. The compensatory blood flow changes, occurring on the LCX when the LAD is occluded, were not significantly modified by any drug treatment. Furthermore, in anaesthetised dogs HR was unchanged during coronary artery occlusion in all groups (Table 2).

\subsection{The severity of ventricular arrhythmias during a $25 \mathrm{~min}$}

\section{occlusion of the $L A D$}

This is illustrated in Fig. 2. In control dogs occlusion of the LAD resulted in high number of VPBs $(310 \pm 45)$ and episodes of VT $(7.1 \pm 1.4)$ that occurred in $93 \%$ of the dogs. Furthermore, $50 \%$ of these control dogs fibrillated during the occlusion and all the remaining animals died on reperfusion, thus there were no survivors in this group from the combined ischaemia and reperfusion insult. In contrast, the administration of simvastatin markedly reduced the number of ectopic beats $(62 \pm 14)$ and episodes of VT $(0.3 \pm 0.2)$, the incidences of VT $(17 \%)$ and VF $(0 \%)$ during occlusion, and $67 \%$ of the animals survived reperfusion. These effects of simvastatin on arrhythmia events were similar to those observed previously (Kisvári et al., 2014). The administration of wortmannin in the simvastatin treated dogs significantly reduced the antiarrhythmic effects of simvastatin. Thus in the presence of wortmannin the number of VPBs $(307 \pm 59)$, the incidence $(73 \%)$ and number of episodes of VT $(4.3 \pm 1.3)$ were again increased, and as with the controls ( $C$ and DMSO groups), no dog in the $\mathrm{W}+\mathrm{S}$ group survived reperfusion. However, wortmannin did not modify the effect of simvastatin on the ischaemia-induced VF; i.e. as with simvastatin alone, no dog in the $\mathrm{W}+\mathrm{S}$ group fibrillated during the occlusion period. It is interesting to note that these results accords with those obtained from studies in which the NOS inhibitor L-NAME was given in the simvastatin treated animals (Kisvári et al., 2014). Compared to the controls (C), neither wortmannin, nor DMSO, the vehicle of wortmannin, affected significantly the severity of arrhythmias resulted from a 25 min occlusion and reperfusion of the LAD. Thus in these groups the number of VPBs was $202 \pm 64$ and $246 \pm 36$, respectively, further $67 \%$ and $69 \%$ of these dogs exhibited $3.8 \pm 1.7$ and $3.8 \pm 1.6$ episodes of VT, and $25 \%$ and $23 \%$ of the animals fibrillated during the occlusion. In both groups none of the dogs survived reperfusion.

\subsection{Changes in ischaemia severity during a 25 min occlusion of the $L A D$}

This was assessed by two parameters; changes in the epicardial ST-segment (Fig. 3A) and in the degree of inhomogeneity of electrical activation (Fig. 3B). In the control groups (C and DMSO) there were marked increases in both epicardial ST-segment and the degree of inhomogeneity over the entire occlusion period. Simvastatin markedly suppressed these indices of ischaemia severity, which effect was completely abolished by the prior administration of wortmannin. Inhibition of the PI 3-kinase/Akt pathway by wortmannin did not significantly influence the ischaemia-induced inhomogeneity and ST-segment changes.

Table 1

Haemodynamic changes following solvent, wortmannin, DMSO and simvastatin administration.

\begin{tabular}{|c|c|c|c|c|c|c|c|c|}
\hline & \multicolumn{2}{|l|}{ Solvent } & \multicolumn{2}{|l|}{ Wortmannin } & \multicolumn{2}{|l|}{ DMSO } & \multicolumn{2}{|l|}{ Simvastatin } \\
\hline & Baseline & Change & Baseline & Change & Baseline & Change & Baseline & Change \\
\hline $\mathrm{SABP}(\mathrm{mm} \mathrm{Hg})$ & $143 \pm 7$ & $3 \pm 2$ & $131 \pm 4$ & $0 \pm 2$ & $135 \pm 6$ & $2 \pm 2$ & $151 \pm 7$ & $-4 \pm 2$ \\
\hline $\mathrm{DABP}(\mathrm{mm} \mathrm{Hg})$ & $105 \pm 5$ & $0 \pm 4$ & $96 \pm 3$ & $0 \pm 2$ & $93 \pm 5$ & $0 \pm 1$ & $103 \pm 4$ & $-2 \pm 2$ \\
\hline MABP (mm Hg) & $118 \pm 5$ & $1 \pm 3$ & $109 \pm 3$ & $0 \pm 2$ & $108 \pm 5$ & $0 \pm 1$ & $119 \pm 5$ & $-4 \pm 1$ \\
\hline $\operatorname{LVSP}(\mathrm{mm} \mathrm{Hg})$ & $154 \pm 7$ & $2 \pm 2$ & $139 \pm 4$ & $1 \pm 2$ & $146 \pm 5$ & $0 \pm 2$ & $163 \pm 7$ & $-1 \pm 2$ \\
\hline LVEDP (mm Hg) & $4.3 \pm 0.6$ & $0.5 \pm 0.3$ & $4.0 \pm 0.5$ & $0.5 \pm 0.5$ & $3.3 \pm 0.4$ & $0.1 \pm 0.2$ & $5.3 \pm 0.4$ & $0 \pm 0.2$ \\
\hline$+\mathrm{dP} / \mathrm{dt}(\mathrm{mm} \mathrm{Hg} / \mathrm{s})$ & $2351 \pm 184$ & $90 \pm 50$ & $2186 \pm 160$ & $-75 \pm 43$ & $2398 \pm 116$ & $61 \pm 55$ & $2787 \pm 180$ & $-79 \pm 98$ \\
\hline$-\mathrm{dP} / \mathrm{dt}(\mathrm{mm} \mathrm{Hg} / \mathrm{s})$ & $2266 \pm 213$ & $40 \pm 81$ & $2443 \pm 159$ & $-5 \pm 112$ & $2676 \pm 181$ & $65 \pm 71$ & $2506 \pm 216$ & $-28 \pm 50$ \\
\hline HR (beats/min) & $163 \pm 7$ & $4 \pm 2$ & $156 \pm 5$ & $-3 \pm 1$ & $156 \pm 4$ & $1 \pm 1$ & $169 \pm 5$ & $-3 \pm 1$ \\
\hline mean $\mathrm{CBF}_{\mathrm{LCX}}(\mathrm{ml} / \mathrm{min})$ & $42 \pm 5$ & $-1 \pm 2$ & $25 \pm 3$ & $3 \pm 2$ & $28 \pm 4$ & $-1 \pm 1$ & $32 \pm 8$ & $1 \pm 2$ \\
\hline
\end{tabular}

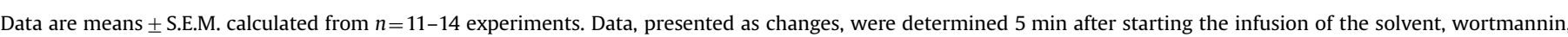

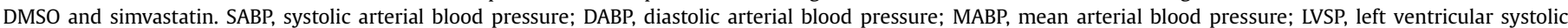
pressure; LVEDP, left ventricular end-diastolic pressure; HR, heart rate; CBF, coronary blood flow. 
Table 2

Haemodynamic changes during a 25 min occlusion of the LAD.

\begin{tabular}{|c|c|c|c|c|c|c|c|c|c|c|}
\hline & \multicolumn{2}{|l|}{ Control } & \multicolumn{2}{|l|}{ Wortmannin } & \multicolumn{2}{|l|}{ DMSO } & \multicolumn{2}{|l|}{ Simvastatin } & \multicolumn{2}{|c|}{ Wortmannin + simvastatin } \\
\hline & Baseline & Max. change & Baseline & Max. change & Baseline & Max. change & Baseline & Max. change & Baseline & Max. change \\
\hline $\mathrm{SABP}(\mathrm{mm} \mathrm{Hg})$ & $146 \pm 7$ & $-10 \pm 2^{\mathrm{a}}$ & $135 \pm 5$ & $-11 \pm 2^{\mathrm{a}}$ & $137 \pm 7$ & $-11 \pm 2^{\mathrm{a}}$ & $148 \pm 5$ & $-11 \pm 2^{a}$ & $155 \pm 8$ & $-10 \pm 2^{a}$ \\
\hline $\mathrm{DABP}(\mathrm{mm} \mathrm{Hg})$ & $105 \pm 5$ & $-10 \pm 3^{a}$ & $99 \pm 4$ & $-8 \pm 1^{\mathrm{a}}$ & $93 \pm 6$ & $-9 \pm 2^{a}$ & $101 \pm 3$ & $-7 \pm 2^{a}$ & $116 \pm 7$ & $-7 \pm 2^{a}$ \\
\hline $\mathrm{MABP}(\mathrm{mm} \mathrm{Hg})$ & $119 \pm 5$ & $-10 \pm 3^{a}$ & $111 \pm 4$ & $-9 \pm 2^{\mathrm{a}}$ & $108 \pm 6$ & $-10 \pm 2^{a}$ & $117 \pm 4$ & $-8 \pm 2^{a}$ & $129 \pm 7$ & $-8 \pm 2^{a}$ \\
\hline LVSP (mm Hg) & $146 \pm 9$ & $-10 \pm 2^{a}$ & $148 \pm 6$ & $-10 \pm 2^{a}$ & $150 \pm 7$ & $-15 \pm 2^{a}$ & $152 \pm 7$ & $-11 \pm 2^{a}$ & $164 \pm 8$ & $-11 \pm 2^{a}$ \\
\hline LVEDP (mm Hg) & $4.5 \pm 0.6$ & $9.3 \pm 1.3^{\mathrm{a}}$ & $4.4 \pm 0.6$ & $9.6 \pm 1.0^{\mathrm{a}}$ & $3.4 \pm 0.5$ & $13.2 \pm 1.0^{\mathrm{a}}$ & $5.2 \pm 0.3$ & $9.0 \pm 0.9^{\mathrm{a}}$ & $4.5 \pm 0.6$ & $9.6 \pm 1.1^{\mathrm{a}}$ \\
\hline$+\mathrm{dP} / \mathrm{dt}(\mathrm{mm} \mathrm{Hg} / \mathrm{s})$ & $2310 \pm 157$ & $-495 \pm 81^{a}$ & $2143 \pm 161$ & $-346 \pm 66^{\mathrm{a}}$ & $2586 \pm 155$ & $-534 \pm 109^{a}$ & $2673 \pm 135$ & $-495 \pm 114^{\mathrm{a}}$ & $2411 \pm 181$ & $-358 \pm 93^{a}$ \\
\hline$-\mathrm{dP} / \mathrm{dt}(\mathrm{mm} \mathrm{Hg} / \mathrm{s})$ & $2316 \pm 200$ & $-425 \pm 139^{a}$ & $2446 \pm 215$ & $-540 \pm 82^{a}$ & $2656 \pm 210$ & $-624 \pm 111^{a}$ & $2563 \pm 183$ & $-504 \pm 91^{a}$ & $2518 \pm 159$ & $-426 \pm 113^{a}$ \\
\hline HR (beats/min) & $166 \pm 7$ & $4 \pm 4$ & $154 \pm 7$ & $1 \pm 2$ & $162 \pm 5$ & $3 \pm 2$ & $167 \pm 4$ & $4 \pm 2$ & $162 \pm 5$ & $4 \pm 2$ \\
\hline mean $\mathrm{CBF}_{\mathrm{LCX}}(\mathrm{ml} / \mathrm{min})$ & $41 \pm 5$ & $13 \pm 2$ & $26 \pm 3$ & $13 \pm 4$ & $30 \pm 3$ & $11 \pm 2$ & $32 \pm 2$ & $10 \pm 1$ & $39 \pm 6$ & $12 \pm 2$ \\
\hline
\end{tabular}

Data are means \pm S.E.M. calculated from $n=11-14$ experiments.

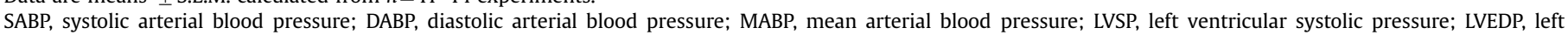
ventricular end-diastolic pressure; $\mathrm{HR}$, heart rate; $\mathrm{CBF}$, coronary blood flow.

${ }^{\text {a }} \mathrm{P}<0.05$ compared to baseline value.

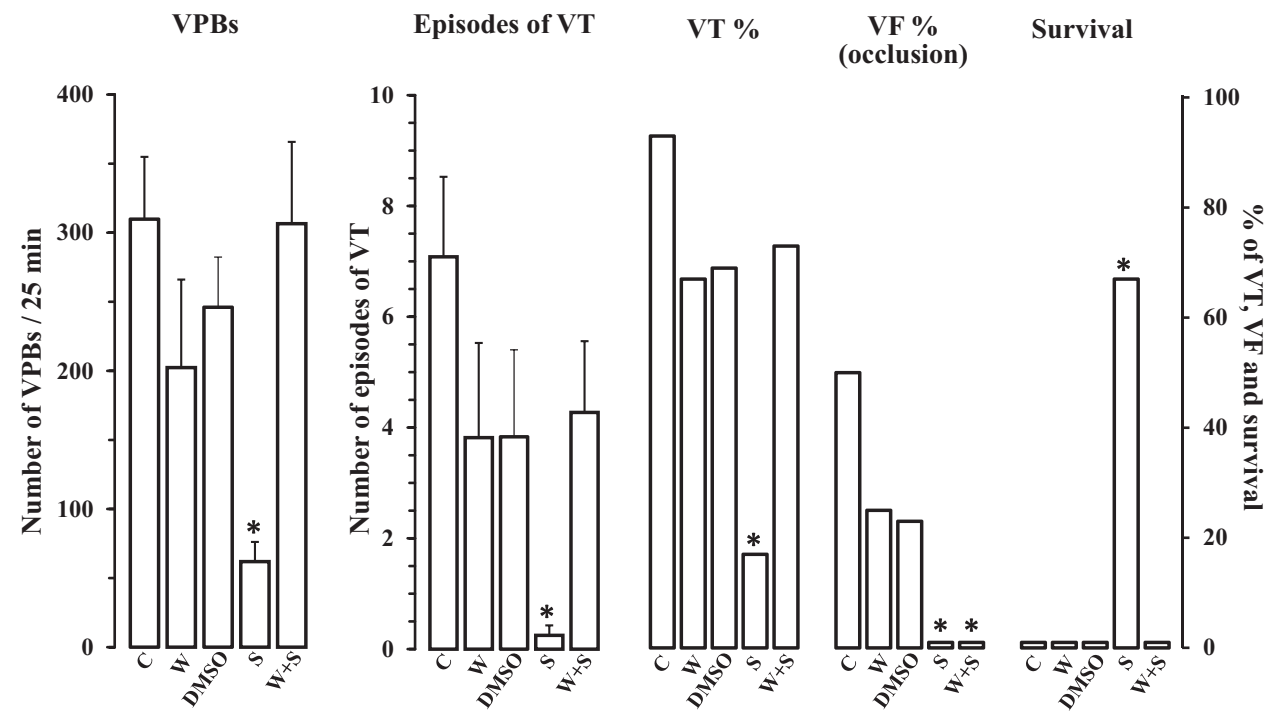

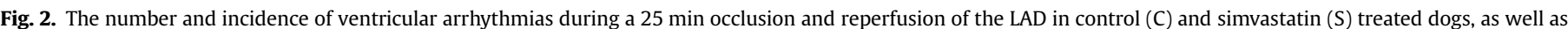

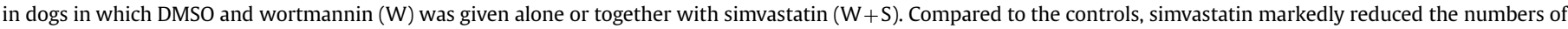

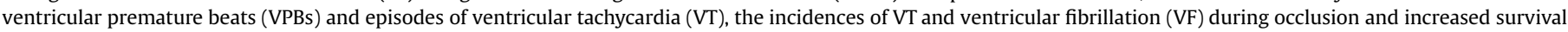

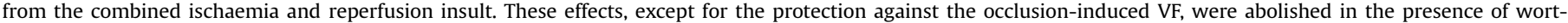

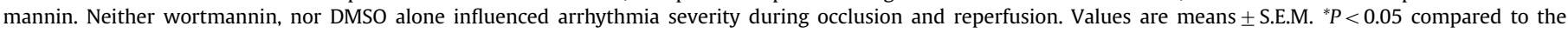
controls.

\subsection{Determination of eNOS activity}

Compared to the sham operated controls (instrumented but not subjected to ischaemia; SC), in dogs, infused either with the solvent of simvastatin (C) or with DMSO and subjected to occlusion, there was a significant decrease in eNOS phosphorylation (Fig. 4A). The administration of simvastatin preserved, and what is more, slightly increased the activity of eNOS during coronary artery occlusion. This effect of simvastatin on eNOS phosphorylation was abolished in the presence of wortmannin ( $W+S$ group), although wortmannin (W group) alone did not affect the ischaemia-induced changes in NOS phosphorylation.

The activation of eNOS through phosphorylation was also determined in dogs that had been subjected to reperfusion (Fig. 4B). Although these data were collected at different times of the reperfusion (according to the occurrence of VF within the $5 \mathrm{~min}$ observation period), the results show that NOS can rapidly regain its activity, when the coronary artery was suddenly reopened. Thus following reperfusion the phosphorylation of eNOS was increased in almost all groups, except those that had been received wortmannin ( $\mathrm{W}$ and $\mathrm{W}+\mathrm{S}$ groups) prior to the 25 min occlusion and reperfusion of the LAD.

\subsection{Changes in $\mathrm{NO}_{x}$ levels during coronary artery occlusion and reperfusion}

These are illustrated in Fig. 5. In control dogs occlusion of the LAD resulted in a transient, but significant increase in $\mathrm{NO}_{\mathrm{x}}$ (peaked around 7 min of the occlusion), followed by a continuous decrease up to the end of the $25 \mathrm{~min}$ occlusion period. This ischaemia-induced reduction in $\mathrm{NO}_{\mathrm{x}}$ was prevented by the application of a single dose of simvastatin. The administration of wortmannin in control dogs abolished the early increase of NO metabolites, and it completely abrogated the NO preserving effect of simvastatin over the entire occlusion period. DMSO had no effect on NO bioavailability during occlusion and reperfusion.

\subsection{Changes in myocardial superoxide production following reperfusion}

In dogs that underwent reperfusion myocardial superoxide production was determined within a 5 min time interval, 
A
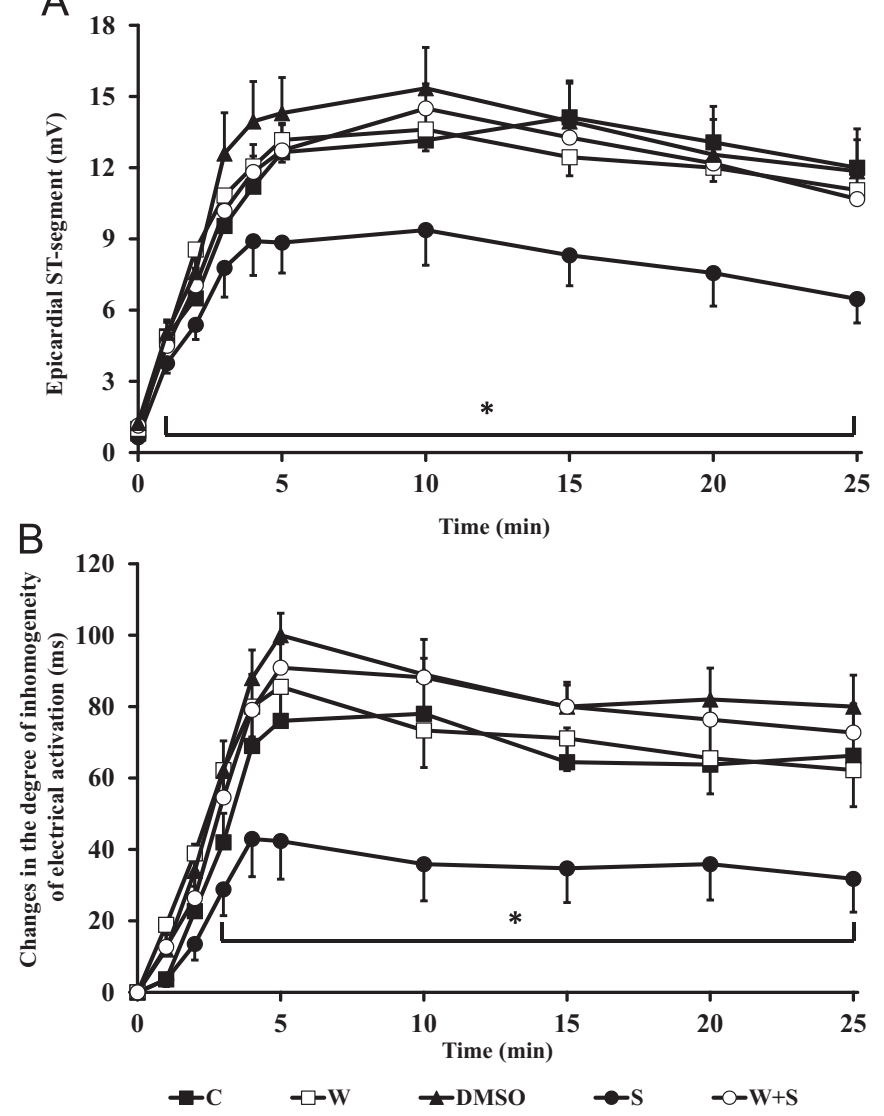

Fig. 3. Changes in epicardial ST-segment (A) and in the degree of inhomogeneity of electrical activation (B) during a 25 min occlusion of the LAD. Compared with controls, simvastatin significantly attenuated both indices of ischaemia severity. These effects of simvastatin were reversed by wortmannin. Neither wortmannin, nor the solvent of wortmannin (DMSO) affected the ischaemia severity, resulting from the occlusion of the LAD. Values are means \pm S.E.M. ${ }^{*} P<0.05$ compared to the controls.

irrespective whether these dogs died or survived. The results are illustrated in Fig. 6. Compared to the sham controls, in dogs subjected to occlusion and reperfusion, there was a marked increase in superoxide production, which was significantly suppressed by simvastatin. The administration of DMSO, as well as of wortmannin itself, did not affect the ischaemia/reperfusion-induced generation of superoxide, but wortmannin reversed the effect of simvastatin on superoxide production.

\subsection{Changes in QTC interval following coronary artery occlusion}

As we have previously described, simvastatin prevents the ischaemia-induced prolongation of the QTC interval, indicating a possible direct electrophysiological effect of the drug (Kisvári et al., 2014). The present results confirm these previous findings, showing that in the presence of wortmannin the effect of simvastatin on the QTC interval is still maintained (Fig. 7).

\subsection{Area at risk}

There were no significant differences in the area at risk among the groups. Thus the risk area was $37 \pm 3 \%$ in the controls, $38 \pm 2 \%$ in the simvastatin, $39 \pm 2 \%$ in the wortmannin, $37 \pm 2 \%$ in the wortmannin + simvastatin and $39 \pm 3 \%$ in the DMSO groups.

\section{Discussion}

We have shown in the previous study that a single dose of simvastatin, applying prior to a 25 min period of coronary artery occlusion in anaesthetised dogs, results in profound protection against those severe ventricular arrhythmias that are, in most instances, responsible for sudden cardiac death (Kisvári et al., 2014). We have also pointed out that this antiarrhythmic effect of simvastatin, at least in part, is mediated through nitric oxide, resulting from an increased activation of endothelial nitric oxide synthase (eNOS) by simvastatin. The evidence for this comes from the observation that the inhibition of NOS by L-NAME attenuated the protective effect of simvastatin against most of the arrhythmia types that resulted from the sudden occlusion and reperfusion of one of the main branches of the left coronary artery. The only arrhythmia event, which was not modified by L-NAME, was the incidence of the occlusion-induced VF. Simvastatin markedly suppressed the occurrence of VF during occlusion, and this effect was apparent, irrespective whether L-NAME was present or not. This finding suggested that in the antifibrillatory effect of simvastatin not only the activation of eNOS, but other mechanisms, perhaps direct electrophysiological effects of the drug, may also play a role (Kisvári et al., 2014). This assumption was supported by the result that L-NAME did not modify the QTc interval reducing effect of simvastatin (Kisvári et al., 2014). The exploration of the possible direct electrophysiological effects of the acute simvastatin treatment warrants further investigations, using more specific methods (e.g. cellular electrophysiology), than our in vivo canine model. Therefore, in the present study we focused on the NOmediated effects of simvastatin, and aimed to investigate further those mechanisms, which participate in the rapid activation of NOS and the subsequent increase in NO bioavailability.

There are studies in the literature, which showed that statins can rapidly activate eNOS by stimulating the phoshatidylinositide 3-kinase/Akt (PI 3-kinase/Akt) pathway (Bell and Yellon, 2003; Wolfrum et al., 2004). For example, in the study of Wolfrum and colleagues (2004), simvastatin given in anaesthetised rats $3 \mathrm{~min}$ prior to reperfusion markedly reduced infarct size that resulted from a 30 min coronary artery occlusion and a subsequent $180 \mathrm{~min}$ period of reperfusion. They also showed that simvastatin increased myocardial PI 3-kinase activity, and enhanced $\mathrm{Akt}_{\text {Ser473 }}$ and eNOS $_{\text {Ser1177 }}$ phosphorylation. Since the infarct size reducing effect of simvastatin was abolished by the administration of the PI 3-kinase inhibitor wortmannin and of the NOS inhibitor L-NAME, they concluded that the activation of PI 3-kinase/Akt/eNOS cascade plays an important role in the acute cardioprotective effects of simvastatin (Wolfrum et al., 2004).

Starting from this prior observation, we designed studies to examine whether in our canine model the activation of the PI 3-kinase/Akt/eNOS pathway plays also a role in the antiarrhythmic effect of the acute simvastatin treatment. We used wortmannin, a potent and specific inhibitor of PI 3-kinase, and administered in dogs prior to the bolus injection of simvastatin. We have found that in the presence of wortmannin most of the salutary effects of simvastatin were attenuated, or even abolished. Thus the number of VPBs, the number of episodes of VT and the incidence of VT during occlusion were again increased, and compared with the simvastatin treated group, in which $40 \%$ of the dogs survived reperfusion, in the wortmannin + simvastatin group $(W+S)$ no animal survived the combined ischaemia and reperfusion insult. However, wortmannin did not influence the suppressing effect of simvastatin on the occlusion-induced ventricular fibrillation. Thus, the marked antifibrillatory effect of simvastatin was still present in dogs co-treated with the PI 3-kinase inhibitor wortmannin. Furthermore, wortmannin did not affect the QTc interval reducing effect of simvastatin (Fig. 7). These findings are very similar to that 

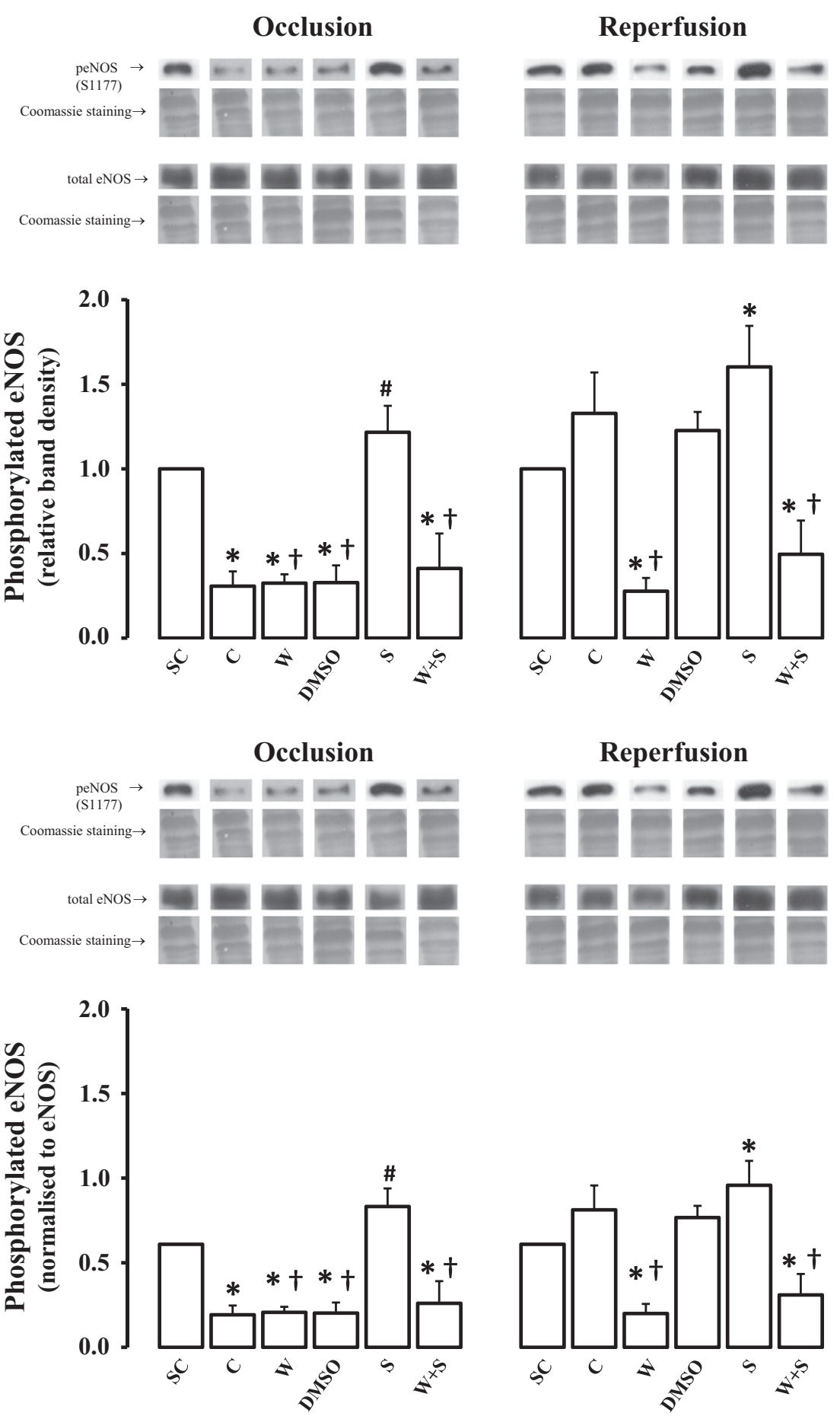

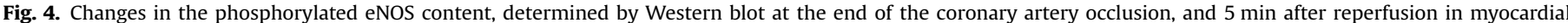

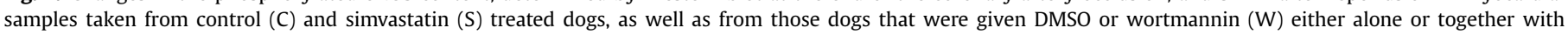

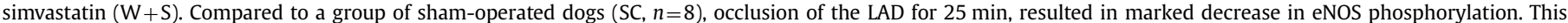

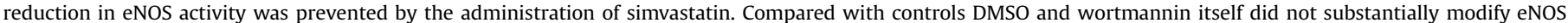

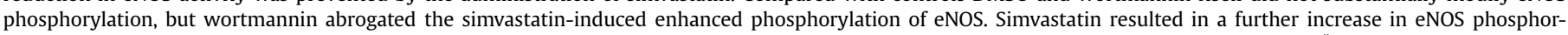

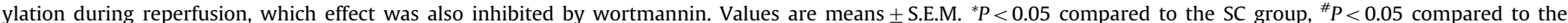
ischaemic control (C) group, and ${ }^{\dagger} P<0.05$ compared to the simvastatin group.

we have previously observed following the administration of L-NAME, which also abolished the protective effect of simvastatin against most of the arrhythmia types, except the reduction in the occlusion-induced VF (Kisvári et al., 2014). Thus the present results confirm our previous supposition that simvastatin may possesses with other, NO-independent effect(s), which do not involve the activation of the PI 3-kinase/Akt/eNOS cascade, but which under ischaemic conditions would influence the occurrence of VF by directly modifying mechanisms, such as cardiac excitability, repolarization, impulse conduction, etc., which are involved in the generation of VF. These possible direct electrophysiological mechanisms have already been discussed in details previously (Kisvári et al., 2014), and there is no worth to repeat them here again.

Nevertheless, we are convinced that the NO-mediated 


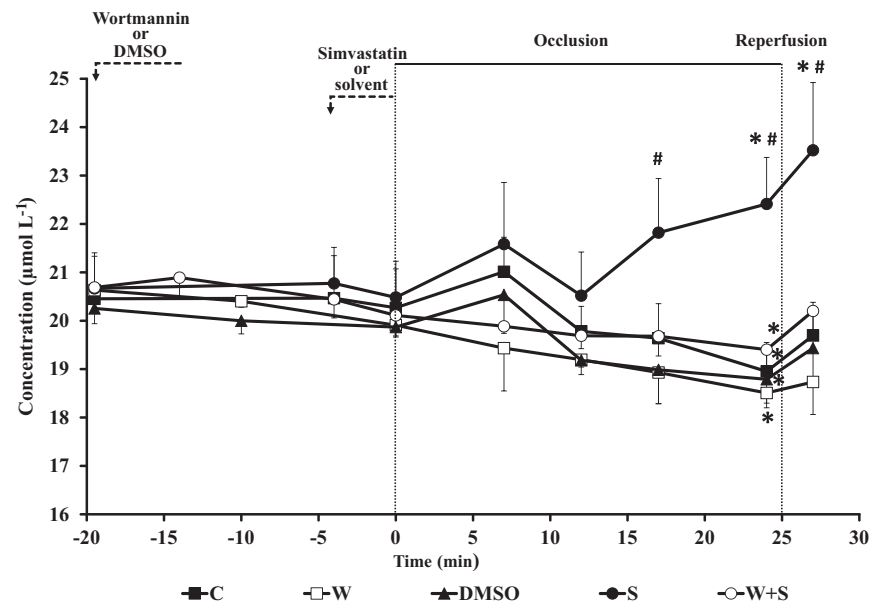

Fig. 5. Changes in plasma nitrite/nitrate $\left(\mathrm{NO}_{\mathrm{x}}\right)$ levels in the blood of the coronary sinus. Occlusion of the LAD in control dogs resulted in a transient elevation (around $7 \mathrm{~min}$ ), followed by a continuous reduction in the concentration of NO metabolites. This was in contrast with the simvastatin treated dogs, where the $\mathrm{NO}_{\mathrm{x}}$ levels were maintained or even increased during the entire occlusion period. In the presence of wortmannin the early elevation of $\mathrm{NO}_{\mathrm{x}}$ in the control dogs, and the enhanced $\mathrm{NO}$ formation in the simvastatin treated dogs were completely abolished, whereas neither wortmannin, nor DMSO given alone modified the production of NO metabolites. Reperfusion caused almost similar increases of $\mathrm{NO}_{\mathrm{x}}$ in all groups. Values are means \pm S.E.M. ${ }^{*} P<0.05$ compared to the initial baseline values, and ${ }^{\#} P<0.05$ compared to the control group.

processes play an essential role in the acute cardioprotective effects of simvastatin, and that the increased NO production following simvastatin treatment results from the rapid activation of eNOS, via the stimulation of the upstream PI 3-kinase/Akt pathway. The evidence for this is that wortmannin, similar to L-NAME (Kisvári et al., 2014), completely abolished the reducing effect of simvastatin on the indices of ischaemia severity, such as the

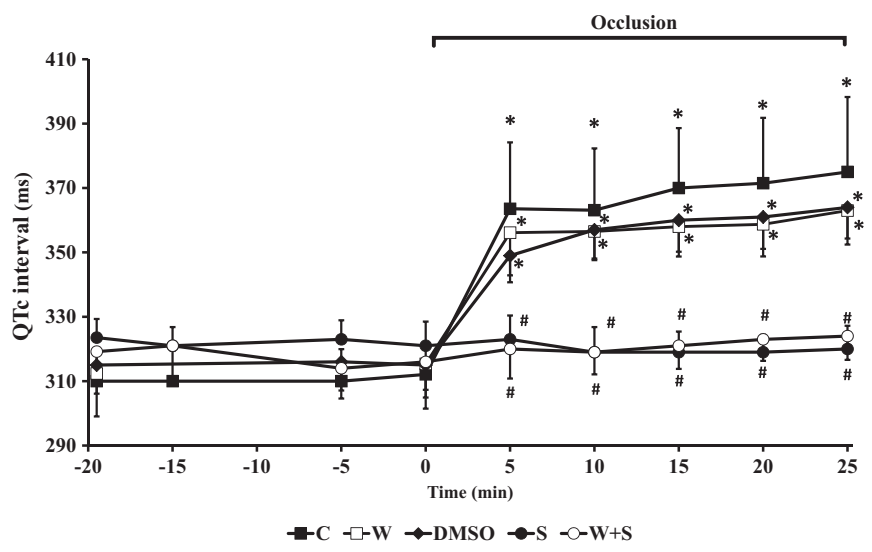

Fig. 7. Changes in the QTc interval determined prior to and during a $25 \mathrm{~min}$ occlusion of the LAD. In control dogs occlusion of the LAD resulted in a significant increase in the QTc interval, which was completely inhibited by the administration of simvastatin. Wortmannin did not influence either the ischaemia-induced prolongation of QTc interval or the inhibitory effect of simvastatin. Values are means \pm S.E.M. ${ }^{*} P<0.05$ compared to the initial baseline values, and ${ }^{\#} P<0.05$ compared to the control group.

epicardial ST-segment and the degree of inhomogeneity of electrical activation (Fig. 3). Also, in the presence of wortmannin, the increased NO production that resulted from simvastatin administration, was again reduced (Fig. 5). It is interesting to note that both L-NAME and wortmannin abolished the transient elevation of NO formation, which was apparent even in the control dogs soon after the commencement of the coronary artery occlusion. This finding suggests three things. First, a short period of ischaemia (e.g. $5 \mathrm{~min}$ ), rapidly activates NOS and results in enhanced NO formation. However, this increase in NO bioavailability is transient, if the ischaemia is maintained over a longer period (e.g. $25 \mathrm{~min}$ ), then the activity of NOS, and consequently, the NO production, are

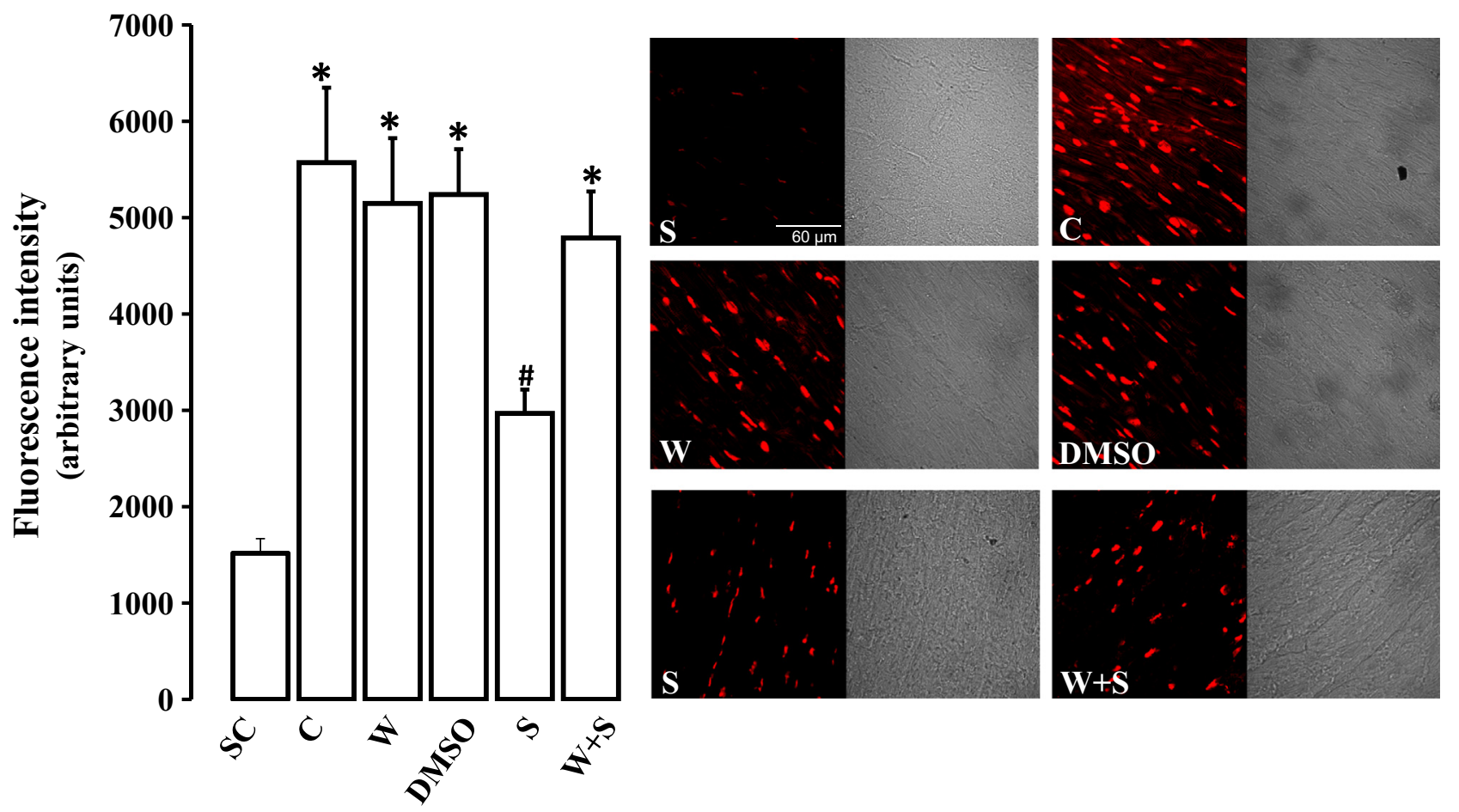

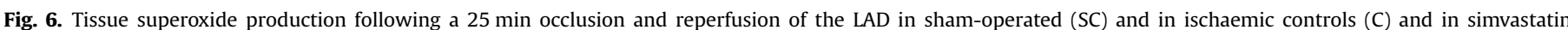

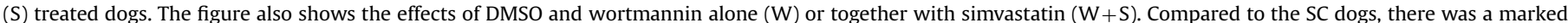

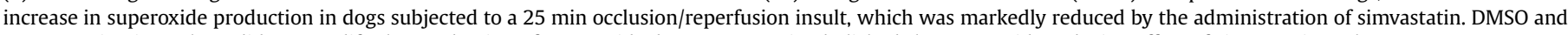

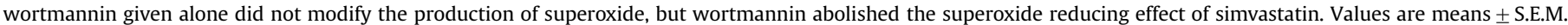
${ }^{*} \mathrm{P}<0.05$ compared to the SC group and ${ }^{\#} P<0.05$ compared to the control (C) group. 
markedly reduced (Juhász et al., 2014). Second, simvastatin, like a short period of ischaemic insult (e.g. preconditioning, Juhász et al., 2014), rapidly activates NOS, but in this case the enzyme remains to be activated even during a longer period of occlusion, resulting in increased levels of $\mathrm{NO}_{\mathrm{x}}$ throughout the prolonged ischaemic insult (Kisvári et al., 2014; Juhász et al., 2014). Thirdly, the activation of NOS, resulting from both the application of simvastatin and a preconditioning stimulus, can be blocked by L-NAME (Végh et al., 1992b; Wolfrum et al., 2004; Kisvári et al., 2014), and also by wortmannin (Tong et al., 2000; Wolfrum et al., 2004). This suggests that there might be a common pathway in NOS activation both by simvastatin and preconditioning. Indeed, there is evidence coming mainly from in vitro experiments that phosphorylation of NOS rapidly modifies NOS activity (Mount et al., 2007). For example, it has been recently reported that in the rat isolated hearts, preconditioning, by stimulating the Akt/protein kinase A (PKA) pathway, activates eNOS via serine 1176 phosphorylation (Yang et al., 2013). There is also evidence that the PI 3-kinase inhibitor wortmannin abolished the preconditioning-induced phosphorylation of protein kinase $\mathrm{B}(\mathrm{Akt})$ and the increase in $\mathrm{NO}$ production in Langendorff-perfused rat hearts (Tong et al., 2000).

In our present experiments, similar to that observed in the study of Wolfrum and colleagues (2004), wortmannin completely blocked the simvastatin-induced phosphorylation of eNOS (Fig. 4) and inhibited NO formation (Fig. 5) during the entire 25 min period of occlusion. We are convinced that NO bioavailability during occlusion plays an essential role in arrhythmia generation both during occlusion and reperfusion (Végh et al., 1992b; Kiss et al., 2010; Gönczi et al., 2009; Juhász et al., 2014; Kisvári et al., 2014). Thus any manoeuvre, which increases or, at least, maintains NO formation during occlusion may protect the myocardium against arrhythmias, most probably through the regulation of those local and systemic mechanisms by NO that are implicated in arrhythmia generation, such as the autonomic tone (Schwartz et al., 1995), gap junctional function (Gönczi et al., 2009; Végh et al., 2013), or the formation of free radicals (e.g. Iwase et al., 2007; Kiss et al., 2010), etc. The latter is particularly important in the generation of the reperfusion-induced severe ventricular arrhythmias, and NO by reducing free radical formation (most likely superoxide) may suppress the occurrence of arrhythmias during reperfusion (Kiss et al., 2010). Since both L-NAME (Kisvári et al., 2014) and, as the present study showed, wortmannin abolished the suppressing effect of simvastatin on the reperfusion-induced superoxide production and subsequently increased the incidence of VF during reperfusion, it seems more than likely that this effect of simvastatin is NO-dependent and it attains via the activation of the PI 3-kinase/Akt/eNOS pathway.

Although these experiments were carefully designed, and performed under controlled conditions, there are some limitations of the present study that worth to be mentioned. First, in this series of experiments the collateral blood flow was not measured. We have previous evidence that in this arrhythmia model, the use of microspheres during the vulnerable, early $(25 \mathrm{~min})$ period of ischaemia can substantially modify arrhythmia severity (Babai et al., 2002). Therefore, we do not attempt to assess tissue blood flow in all of our studies, when the arrhythmias are assessed. However, we assessed the size of that area, which was affected by the occlusion in order to verify similar risk areas in dogs, involved in the various groups. The changes in the severity of ischaemia (epicardial ST-segment, degree of inhomogeneity of electrical activation) over the entire occlusion period were also assessed. Second, we have no direct evidence as to whether the applied dose of wortmannin completely inhibits PI 3-kinase, since in the present study the activity of this enzyme was not determined. At the selection of the dose of wortmannin, we were relied on the data of Wolfrum et al. (2004), who measured PI 3-kinase activity, albeit in a different model. Nevertheless, in this study the intracoronary administration of wortmannin in a dose of $1.5 \mu \mathrm{g} / \mathrm{kg}$, completely abolished all the examined effects of simvastatin, except the reduction in the occlusion-induced ventricular fibrillation and in QTc interval that were apparent in dogs treated with simvastatin, no matter whether wortmannin was present or not. These present and our previous (Kisvári et al., 2014) findings led us to propose that in the antiarrhythmic (antifibrillatory) effect of simvastatin a direct and perhaps NO-independent mechanism may also play a role.

In summary, the present study demonstrates that the antiarrhythmic effect of simvastatin is largely depends on the formation of NO that results from the rapid activation of eNOS via the stimulation of the PI 3-kinase/Akt pathway. The evidence for this is that most of the salutary effects of simvastatin (except the protection against the occlusion-induced VF) are attenuated or even abolished, if PI 3-kinase, one of the upstream components of NOS activation is inhibited with wortmannin. Thus we think that the activation of PI 3-kinase/Akt/eNOS cascade and the subsequent increased formation of NO play a crucial role in the antiarrhythmic effect of acute simvastatin administration, but a direct and presumably NO-independent mechanism cannot also be ruled out.

\section{Acknowledgements}

This work was supported by the Hungarian Scientific Research Foundation (OTKA; Project number K105252). We are also grateful to the excellent technical assistance of Erika Bakó and Irene Biczók.

\section{References}

Altun, I., Oz, F., Arkaya, S.C., Altun, I., Bilge, A.K., Umman, B., Turkoglu, U.M., 2014 Effect of statins on endothelial function in patients with acute coronary syndrome: a prospective study using adhesion molecules and flow-mediated dilatation. J. Clin. Med. Res. 6, 354-361.

Athyros, V.G., Katsiki, N., Karagiannis, A., Mikhailidis, D.P., 2014. Short-, mid-, and long-term benefits of peri-procedural high-intensity statin administration in patients undergoing percutaneous coronary intervention. Curr. Med. Res. Opin. $12,1-5$.

Babai, L., Szigeti, Zs, Parratt, J.R., Végh, Á., 2002. Delayed cardioprotective effects of exercise in dogs are aminoguanidine sensitive: possible involvement of nitric oxide. Clin. Sci. 102, 435-445.

Bell, R.M., Yellon, D.M., 2003. Atorvastatin, administered at the onset of reperfusion, and independent of lipid lowering, protects the myocardium by up-regulating a pro-survival pathway. J. Am. Coll. Cardiol. 41, 508-515.

Chen, J., Nagasawa, Y., Zhu, B.-M., Ohmori, M., Harada, K., Fujimura, A., Hashimoto, K., 2003. Pravastatin prevents arrhythmias induced by coronary artery ischemia/reperfusion in anesthetized normocholesterolemic rats. J. Pharmacol. Sci. 93, 87-94.

Gould, A.L., Davies, G.M., Alemao, E., Yin, D.D., Cook, J.R., 2007. Cholesterol reduction yields clinical benefits: meta-analysis including recent trials. Clin. Ther. 29, 778-794.

Gönczi, M., Kovács, M., Seprényi, Gy, Végh, Á., 2012. The involvement of gap junctions in the delayed phase of the protection induced by cardiac pacing in dogs. Clin. Sci. 123, 39-51.

Gönczi, M., Papp, R., Kovács, M., Seprényi, G., Végh, Á., 2009. Modulation of gap junctions by nitric oxide contributes to the anti-arrhythmic effect of sodium nitroprusside. Br. J. Pharmacol. 156, 786-793.

Hernández-Perera, O., Pérez-Sala, D., Navarro-Antolín, J., Sánchez-Pascuala, R., Hernández, G., Díaz, C., Lamas, S., 1998. Effects of the 3-hydroxy-3-methylglutaryl-CoA reductase inhibitors, atorvastatin and simvastatin, on the expression of endothelin-1 and endothelial nitric oxide synthase in vascular endothelial cells. J. Clin. Investig. 101, 2711-2719.

ILAR (Institute of Laboratory Animal Resources), 1996. Guide for the Care and Use of Laboratory Animals. National Academy Press, Washington D.C (NIH Publication No. 85-23).

Iwase, H., Robin, E., Guzy, R.D., Mungai, P.T., Vanden Hoek, T.L., Chandel, N.S., Levraut, J., Schumacker, P.T., 2007. Nitric oxide during ischemia attenuates oxidant stress and cell death during ischemia and reperfusion in cardiomyocytes. Free Radic. Biol. Med. 43, 590-599.

Juhász, L., Déri, Sz, Kisvári, G., Kiss, A., Seprényi, Gy, Gardi, J., Végh, Á., 2014. The effect of preconditioning on nitric oxide synthase activity during myocardial ischemia and reperfusion in anesthetized dogs. Curr. Res. Cardiol. 1, 73-78. 
Kiss, A., Juhász, L., Seprényi, G., Kupai, K., Kaszaki, J., Végh, Á., 2010. The role of nitric oxide, superoxide and peroxynitrite in the anti-arrhythmic effects of preconditioning and peroxynitrite infusion in anaesthetized dogs. Br. J. Pharmacol. $160,1263-1272$

Kisvári, G., Kovács, M., Gardi, J., Seprényi, Gy, Kaszaki, J., Végh, Á., 2014. The effect of acute simvastatin administration on the severity of ventricular arrhythmias resulting from ischaemia and reperfusion in the canine: is there a role for nitric oxide? Eur. J. Pharmacol. 732, 96-104.

Kovács, M., Gönczi, M., Kovács, E., Végh, Á., 2013. Time course analysis of cardiac pacing-induced gene expression changes in the canine heart. Mol. Cell. Biochem. 372, 257-266.

Kureishi, Y., Luo, Z., Shiojima, I., Bialik, A., Fulton, D., Lefer, D.J., Sessa, W.C., Walsh, K. 2000. The HMGCoA reductase inhibitor simvastatin activates the protein kinase Akt and promotes angiogenesis in normocholesterolemic animals. Nat. Med. 6, 1004-1010.

Laufs, U., Fata, V.L., Liao, J.K., 1997. Inhibition of 3-hydroxy-3-methylglutaryl (HMG)-CoA reductase blocks hypoxia-mediated down-regulation of endothelial nitric oxide synthase. J. Biol. Chem. 272, 31725-31729.

Laufs, U., Liao, J.K., 1998. Post-transcriptional regulation of endothelial nitric oxide synthase mRNA stability by Rho GTPase. J. Biol. Chem. 273, 24266-24271.

Lefer, A.M., Scalia, R., Lefer, D.J., 2001. Vascular effects of HMG CoA-reductase inhibitors (statins) unrelated to cholesterol lowering. New concepts for cardiovascular disease. Cardiovasc. Res. 49, 281-287.

Mount, P.F., Kemp, B.E., Power, D.A., 2007. Regulation of endothelial and myocardial NO synthesis by multi-site eNOS phosphorylation. J. Mol. Cell. Cardiol. 42, 271-279.

Schwartz, P.J., Diem, R., Dun, N.J., Forstermann, U., 1995. Endogenous and exogenous nitric oxide inhibits norepinephrine release from rat heart sympathetic nerves. Circ. Res. 77, 841-848.

Sever, P.S., Poulter, N.R., Dahlof, B., Wedel, H., Beevers, G., Caulfield, M., Collins, R., Kjeldsen, S.E., Kristinsson, A., McInnes, G., Mehlsen, J., Nieminen, M.S., O'Brien, E.T., Ostergren, J., ASCOT Investigators, 2008. The anglo-scandinavian cardiac outcomes trial lipid lowering arm: extended observations 2 years after trial closure. Eur. Heart J. 29, 499-508.

The Long-Term Intervention with Pravastatin in Ischaemic Disease (LIPID) Study Group, 1998. Prevention of cardiovascular events and death with pravastatin in patients with coronary heart disease and a broad range of initial cholesterol levels. N. Engl. J. Med. 339, 1349-1357.

Tong, H., Chen, W., Steenbergen, C., Murphy, E., 2000. Ischemic preconditioning activates phosphatidylinositol-3-kinase upstream of protein kinase C. Circ. Res. 87, 309-315.

Végh, Á., Gönczi, M., Miskolczi, G., Kovács, M., 2013. Regulation of gap junctions by nitric oxide influences the generation of arrhythmias resulting from acute ischemia and reperfusion in vivo. Front. Pharmacol. 4 (article76).

Végh, Á., Komori, S., Szekeres, L., Parratt, J.R., 1992a. Antiarrhythmic effects of preconditioning in anaesthetised dogs and rats. Cardiovasc. Res. 26, 487-495.

Végh, Á., Szekeres, L., Parratt, J.R., 1992b. Preconditioning of the ischaemic myocardium; involvement of the l-arginine nitric oxide pathway. Br. J. Pharmacol. 107, 648-652.

Walker, M.J., Curtis, M.J., Hearse, D.J., Campbell, R.W., Janse, M.J., Yellon, D.M., Cobbe, S.M., Coker, S.J., Harness, J.B., Harron, D.W., Higgins, A.J., Julian, D.G., Lab, M.J., Manning, A.S., Northover, B.J., Parratt, J.R., Riemersma, R.A., Riva, E., Russell, D.C., Sheridan, D.J., Winslow, E., Woodward, B., 1988. The Lambeth conventions: guidelines for the study of arrhythmias in ischaemia infarction, and reperfusion. Cardiovasc. Res. 22, 447-455.

Wang, X., Lin, Y., Luo, N., Chen, Z., Gu, M., Wang, J., Chen, Y., 2014. Short-term intensive atorvastatin therapy improves endothelial function partly via attenuating perivascular adipose tissue inflammation through 5-lipoxygenase pathway in hyperlipidemic rabbits. Chin. Med. J. (Engl.) 127, 2953-2959.

Wolfrum, S., Dendorfer, A., Schutt, M., Weidtmann, B., Heep, A., Tempel, K., Klein, H. H., Dominiak, P., Richardt, G., 2004. Simvastatin acutely reduces myocardial reperfusion injury in vivo by activating the phoshatidylinositide 3-kinase/Akt pathway. J. Cardiovasc. Pharmacol. 44, 348-355.

Yang, C., Talukder, M.A.H., Varadharaj, S., Velayutham, M., Zweier, J.L., 2013. Early ischaemic preconditioning requires Akt- and PKA-mediated activation of eNOS via serine1176 phosphorylation. Cardiovasc. Res. 97, 33-43. 